\title{
Radon measurements in dwellings: Study in the Vaud canton (Switzerland)
}

\author{
T. Buchillier and J.-F. Valley
}

Institut de radiophysique appliquée, CH-1015 Lausanne, Switzerland

\begin{abstract}
Since 1994 the Swiss radiological protection ordinance provides a limit for radon concentrations in inhabited premises. Radon measurements are made in all cantons of Switzerland in order to find out the regions with high radon levels and when necessary to take remedial actions on the affected buildings. For the Vaud canton a sampling of at least 3000 houses all over the territory is desirable to establish this classification. The preliminary results obtained after several measurement campaigns show radon levels comparable to those in the nonaffected areas elsewhere in Switzerland.
\end{abstract}

\section{Introduction}

\section{Origin of radon}

Radon is a gas coming from uranium traces present in the earth surface. It is produced in the soil where it can diffuse and reach the surface before decaying.
The earth crust contains a small quantity of uranium-238 since its formation $5 \times 10^{9}$ years ago which is decaying slowly through many radionuclides until stable lead-206 is formed (Fig. 1). One of these radionuclides, radon-222, is a gas. The outdoor concentration of radon always remains very low due to the large dilution of the gas and because of its short half-live $(3.8 \mathrm{~d})$. However inside houses into which radon is penetrating through the openings in the concrete basement structure, the concentration can reach high levels because air exchange is reduced. The quantity of radon present in the soil gas depends on the quantity of ${ }^{238} \mathrm{U}$ in the rock, on the grains size and on the emanation fraction [1]. The ability of soil gas to circulate in the underground on several meters below and around the building is also of critical importance. The soil porosity and the radon availability are therefore the dominant geological parameters allowing for high radon levels in a building. The radon supply due to building materials and tap water has shown to be only of a minor contribution in Switzerland [2].

\section{Sanitary effects}

The health effects of radon are caused by its four radioactive decay products inhaled and deposited in the lungs where 


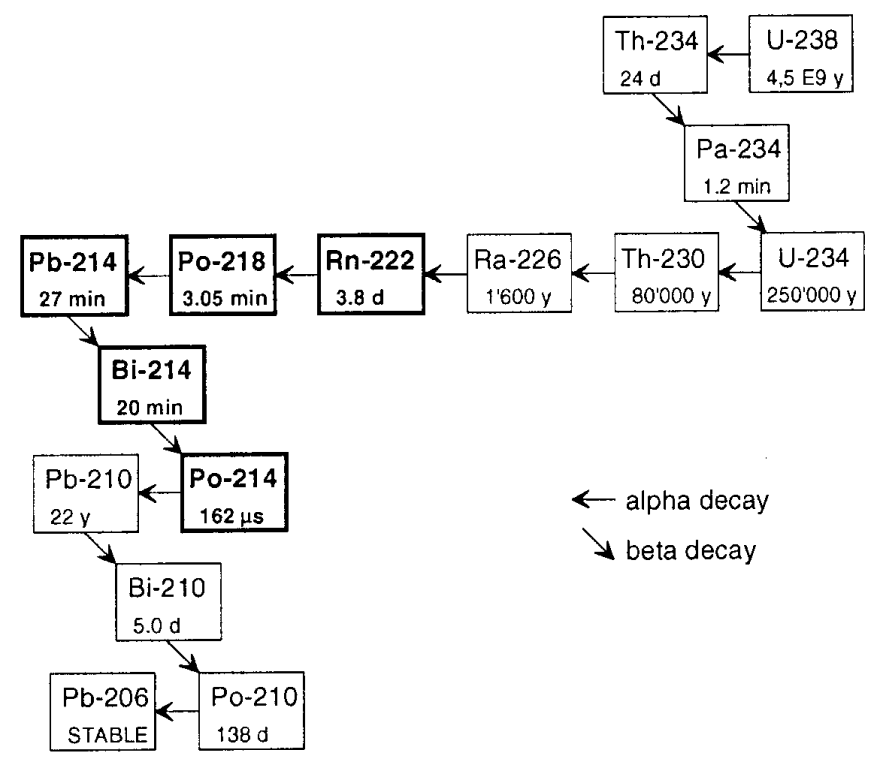

Figure 1. Radionuclides of the ${ }^{238} \mathrm{U}$ decay chain with corresponding half-lives $(y=$ years, $d=$ days, $\min =$ minutes, $s=$ seconds).

they irradiate the pulmonary tissues. The associated risk is the induction of lung cancer after 10 to 20 years of latency.

During the past 20 years the concern about this risk has grown and epidemiological studies have been conducted to assess the relation between radon exposure and lung cancer rate.

Risk factors have been estimated in epidemiological studies, mainly on minors populations but also in the general population. However the transfer of results concerning minors is not completely valid because of the absence of a model describing the details of the interactions of radon decay products in the lungs and the influence of other pollutants to which minors are exposed. Case-control studies in the general population show contradictory results at low exposure but it is generally recognised that exposition to high levels of radon produces an excess of lung cancer risk and hence should be avoided [3].

\section{Legal aspects}

Some countries have specified recommendations and even limits concerning radon concentration in inhabited premises. In Switzerland the Radiological Protection Ordinance is setting a legal limit at $1000 \mathrm{~Bq} / \mathrm{m}^{3}$ and a recommendation at $400 \mathrm{~Bq} / \mathrm{m}^{3}$ for new buildings and renovations.

According to this ordinance the cantons have to make a sufficient number of measurements all over their territory to localise the regions with high concentrations (radon area).

\section{Material and methods}

\section{Measurement techniques}

Most of the usual radiation detection techniques like ionisation chambers, semiconductor, scintillation and alpha-track detectors are used for radon measurements. Many commercial integrating devices exist that can easily be sent by mail to the house occupants. A short description of the 3 types of detectors used during our successive measurement campaigns is given below. A review of the available instruments for radon and radon progeny measurements can be found in [4].

\section{Charcoal detectors}

Charcoal detectors are based on the adsorption of radon in charcoal during the exposure period. They are made of a small vial containing a capsule in the upper part with a certain amount of activated charcoal grains. The vial is left open for 1-2 days in the room and then recapped and sent back for analysis. The evaluation consists in the elution of radon from the charcoal with a toluene-based scintillation liquid. When the activity of the decay products is in equilibrium with radon (i.e. after a minimum of 8 hours), the vial is counted in a liquid scintillation counter where both alpha and beta radiation are detected. The radon activity in air is related to the activity in the vial by the calibration factor and is corrected for decay during the time period between exposure and analysis. This type of detector can only be exposed for a few days because a dynamic equilibrium is reached between radon entering and leaving the charcoal.

\section{Alpha-track detectors}

They are made of a small box in which filtered air containing radon diffuses. The alpha particles produced by the decay of radon and its progeny inside the chamber create impacts on a solid-state material such as cellulose nitrate (LR-115) or allyl diglycol carbonate (CR-39) plastic films. After exposure, the tracks are made visible by electrochemical etching. The track number is determined using a microscope by manual scanning and counting or by means of an automatic optical scanning system. This complex process is carried out by the detector supplier.

\section{Electret ionisation chambers}

They are made of a conductive plastic chamber containing an electret [5,6]. Filtered air containing radon diffuses into the chamber and the radiation produced by radon and its progeny generates ions that are collected by the charged electret. The electret voltage decreases in proportion to the integrated radon concentration. A voltage reader is used to measure the electret surface voltage. Several combinations of chamber size and electret sensitivity can be used for different exposure time or concentration levels. The advantage of this type of detector is that the evaluation can be 
performed in the field and the electrets can be reused many times as long as the remaining charge is sufficient for another exposure.

\section{Measurement procedure}

Usually two detectors are placed in each house, one in the basement and the other in the living room or bedroom located on the lowest level. Measurement period is preferably winter (October to March) because radon concentrations are higher in the cold season due to the pressure differentials caused by heating and because of the reduced ventilation.

The detectors are mailed to the house occupants together with instructions for use and a small questionnaire to collect the most important characteristics of the house influencing the radon concentration.

Radon concentration fluctuates from day to day depending on the atmospheric conditions. For this reason, the exposure time extends to 2-3 months, except for charcoal detectors for which it lasts 1-2 days only.

The quality assurance program is based on an annual verification of five random detectors in the radon chamber at Paul Scherrer Institut in Villigen [7].

\section{Measurement campaigns}

\section{Preliminary measurements}

Since 1991, several preliminary campaigns have been organised in the Vaud canton, with a total number of 1000 houses examined, before the Radiological Protection Ordinance came into force. They aimed at obtaining a general information on the situation in this canton and also at testing the short term detectors (charcoal) as compared to the long term detectors (alpha-track). Restrained areas of the canton were also examined in the Jura region and the Pre-Alps region.

A satisfactory agreement between long term measurements and the average of 3 short-term measurements repeated during the same period was obtained. An overestimation of $35 \%$ with charcoal can be explained by ventilation restrictions imposed before and during the measurement. A survey on the Jura chain with short term detectors (1 day) showed slightly higher concentration for this region than for the Plateau. Still in the Jura, a survey in two villages close to each other showed that very large variations of radon concentration can be encountered between houses separated by only a few tens of meters. A survey in the PreAlps region gave similar values to those found on the Jura.

These first experiences on radon measurements confirmed the impossibility to predict the concentration according to the geological map because the latter doesn't describe the ground down to a scale of a few meters. Each house has to be considered individually.

\section{$1997 / 98$ study}

The Vaud canton with a population of 606000 and a stock of 100000 buildings has to be covered by at least 3000 measured houses. This number is calculated by establishing 150 zones in the canton and sampling each of them with about 20 measurements. This means that the number of measurements obtained during the preliminary program had to be increased by a factor 3 .

In December 1997, an information to the general population concerning radon was organised through the media giving the possibility to anyone to have a radon control at home. About nine hundred people asked for this control which was carried out in two successive campaigns from December 1997 to May 1998. Another 400 measurements were made in schools (classrooms and basements) from April to June 1998.

\section{Results}

The collection of all measurements (preliminary and this work) in inhabited rooms gives a mean radon concentration in the Vaud canton of $100 \mathrm{~Bq} / \mathrm{m}^{3}$. The concentration distribution is approximately log-normal as shown in figure 2 .

Five percent of the houses are above the recommendation value of $400 \mathrm{~Bq} / \mathrm{m}^{3}$ and $0.2 \%$ are above the limit of $1000 \mathrm{~Bq} / \mathrm{m}^{3}$. The mean concentrations observed in the districts are given in table I and illustrated in figure 3 . None of them presents a mean value exceeding $200 \mathrm{~Bq} / \mathrm{m}^{3}$, the limit which would define a "radon area".

\section{Discussion and conclusion}

The mean radon concentration in inhabited premises observed until now in the Vaud canton, $100 \mathrm{~Bq} / \mathrm{m}^{3}$, is close to the mean value of $80 \mathrm{~Bq} / \mathrm{m}^{3}$ announced by the Swiss

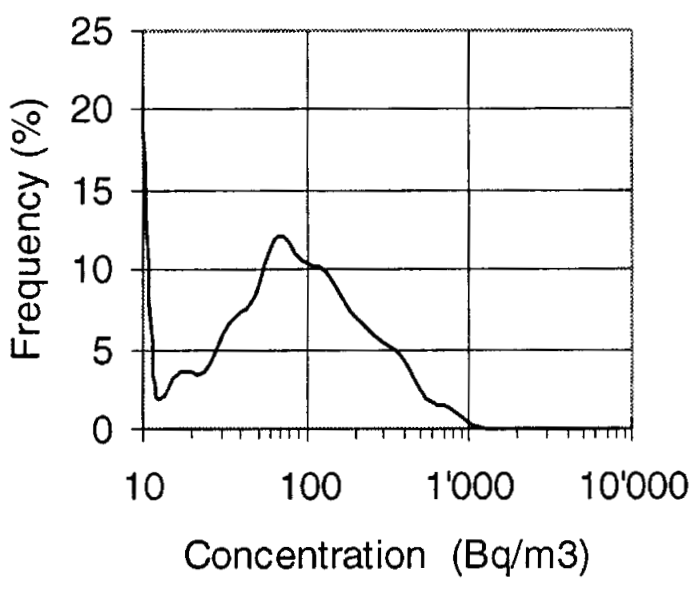

Figure 2. Distribution of radon concentration 
Table I. Mean radon concentration for the different districts.

\begin{tabular}{lcc}
\hline District & $\begin{array}{c}\text { Number of } \\
\text { measurements }\end{array}$ & $\begin{array}{c}\text { Mean concentration } \\
\left(\mathrm{Bq} / \mathrm{m}^{3}\right)\end{array}$ \\
\hline Aigle & 226 & 137 \\
Aubonne & 92 & 88 \\
Avenches & 29 & 89 \\
Cossonay & 134 & 103 \\
Echallens & 92 & 94 \\
Grandson & 105 & 110 \\
Lausanne & 393 & 82 \\
Lavaux & 88 & 101 \\
Morges & 177 & 103 \\
Moudon & 45 & 107 \\
Nyon & 165 & 92 \\
Orbe & 157 & 92 \\
Oron & 66 & 112 \\
Payerne & 39 & 162 \\
Pays d'Enhaut & 42 & 108 \\
Rolle & 33 & 54 \\
Vallée & 59 & 119 \\
Vevey & 114 & 65 \\
Yverdon & 155 & 87 \\
Total & 2211 & - \\
Average & - & 100 \\
\hline
\end{tabular}

Federal Office for Public Health and based on the collection of all measurements in Switzerland. On the Jura chain and in the Pre-Alps region, the values seem to be slightly higher. Surprisingly, the highest mean district concentration is found in the Plateau region in the district of Payerne. However there is an important lack of measurements in this district and the present result is not really representative. The two regions with the lowest concentrations are located close to the Lake Léman (Rolle and Vevey). Like in Lausanne, the measurements in these districts might include more recent buildings than in rural regions, explaining the lowest values.

The measurement program is going on in many regions where a representative number of houses has not been

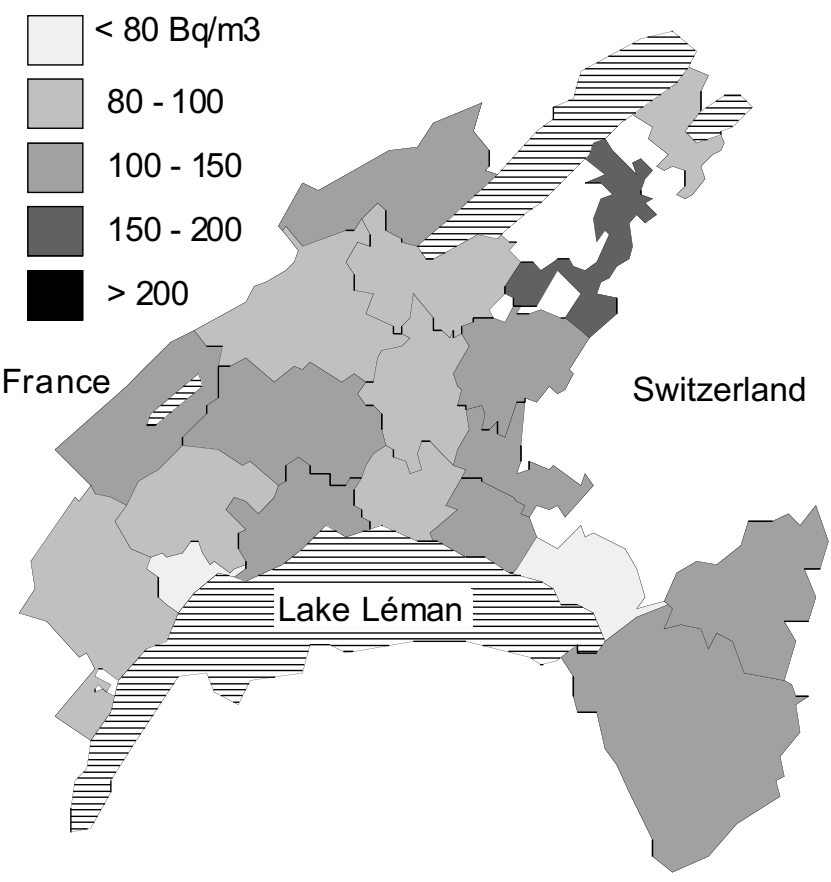

Figure 3. Radon concentrations

obtained yet with the objective to draw the detailed radon chart before the year 2004.

\section{References}

1. Nero, A. V. Jr. In: Radon and its decay products in indoor air; (Nazaroff, W. W.; Nero, A. V. Jr., Eds.) John Wiley, New York, 1988; pp 57-112.

2. Federal Office of Public Health, Radonprogramm Schweiz "RAPROS", Bericht über die Ergebnisse der Jahre 1987-1991, Division of radioprotection, CH-3003 Bern, 1992.

3. ICRP Publication 60, Annals of the ICRP, 1990 Recommendations of the International Commission on Radiological Protection; Pergamon Press, Oxford, 1993.

4. George, A. C., Health Phys. 1996, 70(4), 451-463.

5. Kotrappa, P. et al. Health Phys. 1988, 54(1), 47-56.

6. Kotrappa, P. et al. Health Phys. 1990, 58(4), 461-467.

7. Paul Scherrer Institut, Die Vergleich Messung 1997 für Radongasmessgeräte am PSI, PSI Bericht Nr. 98-05, CH-5232 Villigen, 1998. 